Vietnam Academy of Science and Technology
Vietnam Journal of Earth Sciences
http://www.vjs.ac.vn/index.php/jse

\title{
Assessment and Simulation of Impacts of Climate Change on Erosion and Water Flow by Using the Soil and Water Assessment Tool and GIS: Case Study in Upper Cau River basin in Vietnam
}

\author{
Tran Hong Thai*1, Nguyen Phuong Thao², Bui Tien Dieu \\ ${ }^{1}$ National Hydro-Meteorological Service, No. 4 Dang Thai Than street, Hoan Kiem District, Hanoi, Vietnam \\ ${ }^{2}$ Vietnam Institute of Meteorology, Hydrology and Climate change, No. 23, Lane 62, Nguyen Chi Thanh street, Dong \\ Da district, Hanoi, Vietnam \\ ${ }^{3}$ Geographic Information System Group, Department of Business and IT, University College of Southeast Norway, \\ Gullbringvegen 36, N-3800 BøiTelemark, Norway
}

Received 27 May 2017. Accepted 01 September 2017

\section{ABSTRACT}

The Upper Cau river basin that plays an important role in socio-economic developments the North of Vietnam is sensitive to changes of climate influencing flows, erosion, and water resources. The main objective of this study is to assess and simulate impacts of climate change on erosion and water flow in the basin. Using a GIS database, Soil, and Water Assessment Tool (SWAT) model, the water flow, and soil loss assessed with data in period 1980-1999 called the base period, then simulated until 2100 considering the medium emission scenario (B2). The simulation results showed that the total annual runoff and soil loss tends to increase compared to the base period. For flow, the change rate of the simulation period is higher than the base period; the water flow rate will increase by $0.22 \%$ ( 2020 2039 ) and up to $1.37 \%(2080-2100)$. The total annual soil loss of the simulation period at Gia Bay station tends to increase steadily compared to the baseline, namely by $6.2 \%(2020-2039)$ and $25.5 \%(2080-2100)$. Overall, the result in this study shows that effects of climate changes on the basin are severe enough under the scenario B2 that is useful for authorities for basin management.

Keywords: Water flow; Erosion; Soil loss; Climate Change; Upper Cau River basin.

(C)2017 Vietnam Academy of Science and Technology

\section{Introduction}

Changes in climate have been observed in the past decades and have significant impacts on hydrologic cycles and affecting water resources systems (Ali et al., 2012; Arnell, 2004; Beare and Heaney, 2002; McBean and

"Corresponding author, Email: tranthai.vkttv@gmail.com
Motiee, 2008; Ouyang et al., 2017; VargasAmelin and Pindado, 2014). It has proven that more changes will be projected for the coming decades and will cause negative effects to many areas in the world (IPCC, 2007).

For the case of Vietnam, changes of climates and unequal distribution of water resources are a pressing issue in many basin areas (Liem et al., 2011). Particularly, the Upper 
Tran Hong Thai, et al./Vietnam Journal of Earth Sciences 39 (2017)

Cau river basin, which has a significant socioeconomic role in the North of Vietnam, is facing water resource problems both the quantity and quality due to flood problems in the wet season and drought problems in the dry season. In addition, soil erosion is another problem in this area. In general, these problems seem to be more severe in the future (Phan, D.B. et al., 2011). Therefore, assessment and simulation of impacts of climate change on erosion and water flow for the basin are an urgent task. This is considered a key issue that assists local authorities in decision-making and management in the basin.

Thus, the objectives of the study are to give the quantitative assessment of the changes of the surface water flow and the level of erosion of Upper Cau river basin under the impacts of climate change. Thereby, some policy management based on the results could be proposed for the study area. This study addresses this issue by assessing and simulating impacts of climate change on erosion and water flow in the Upper Cau River basin (Vietnam). According to ICCP (IPCC, 2000), 40 climate change scenarios could be assessed and simulated considering relatively diversified possibilities of GHG emissions in the $21^{\text {st }}$ century. These scenarios could be grouped into 4 categories namely A1, A2, B1, B2 (IPCC, 2000), (MONRE, 2009). In which, B2 scenario is the one that has continuously increasing population, but at a rate lower than A2; the emphasis is on local rather than global solutions to economic, social and environmental sustainability; intermediate levels of economic development; less rapid and more diverse technological change than in B1 and A1 families (medium emission scenario, in the same group of A1B). Moreover, the reports of Vietnam Ministry of Natural Resources \& Environment (MONRE, 2012) state that the scenario B2 that is the emphasis on local solutions should be used. Though this is not the latest version of climate change scenario (MONRE, 2016), because of the limitation of data availability, the study chose the scenario B2 to simulate the impacts of climate change on erosion and water flow for the study area. It is noted that the simulation and prediction were carried out using the Soil and Water Assessment Tool (SWAT) and Geographic Information System (GIS).

\section{Materials and Methods}

\subsection{Description of the study area}

The study area is the Upper Cau river basin that belongs to the Hong-Thai Binh river basin, a big basin in the northern Vietnam (Figure 1). The Upper Cau river basin restricted at Gia Bay station with the total area of $2,835 \mathrm{~km}^{2}$ is located in Bac Kan and Thai Nguyen provinces. The basin has varied and complex terrain in the direction of northwest southeast, characterized by two types of mountainous and midland. It has some major soil groups including rocky-inert erosion, boggy and slope-convergent, yellow red, and mountainous red yellow humus. Stream and river networks are quite developed with the network density reach $0.7-1.2 \mathrm{~km} / \mathrm{km}^{2}$. The main tributaries distribute evenly along the main river.

The Rainy season lasts from May to October, while the dry season is from November to April of the following year. In the rainy season, rainfall accounts for $75-80 \%$ of the total annual rainfall and months with the heaviest precipitation are July and August with rainfall distributed over $300 \mathrm{~mm} /$ month. The months having the lowest rainfall are December and January. Rainfall is unevenly distributed and dependent on the topography of each region. Due to unevenly rainfall distribution, two seasons are recognized. Flood season is from June to October and accounts for $70-80 \%$ of 
Vietnam Journal of Earth Sciences, 39(4), 376-392

the total annual flow. The dry season lasts for 7-8 months, from November to May of the following year and accounts for only $20-30 \%$ of the total annual flow. The groundwater source is not rich. The water quality of the Cau River in most of the local areas is unsatisfactory for domestic purposes. Still, the water quality of upstream rivers is relatively stable.

\subsection{Data used}

For this study, monitoring data provided by MONRE for the 1980-1999 periods at three meteorological stations (Dinh Hoa, Thai Nguyen and Bac Kan) and one hydrological station (Gia Bay) in the Upper Cau River basin were used. In addition, other data such as a digital elevation model (DEM), land use, and soil type were also collected and processed. Consequently, a total of 10 input factors were prepared including a digital elevation model (DEM), land use, soil type, rainfall, temperature, solar radiation, relative humidity, wind speed, discharge and sediment discharge.

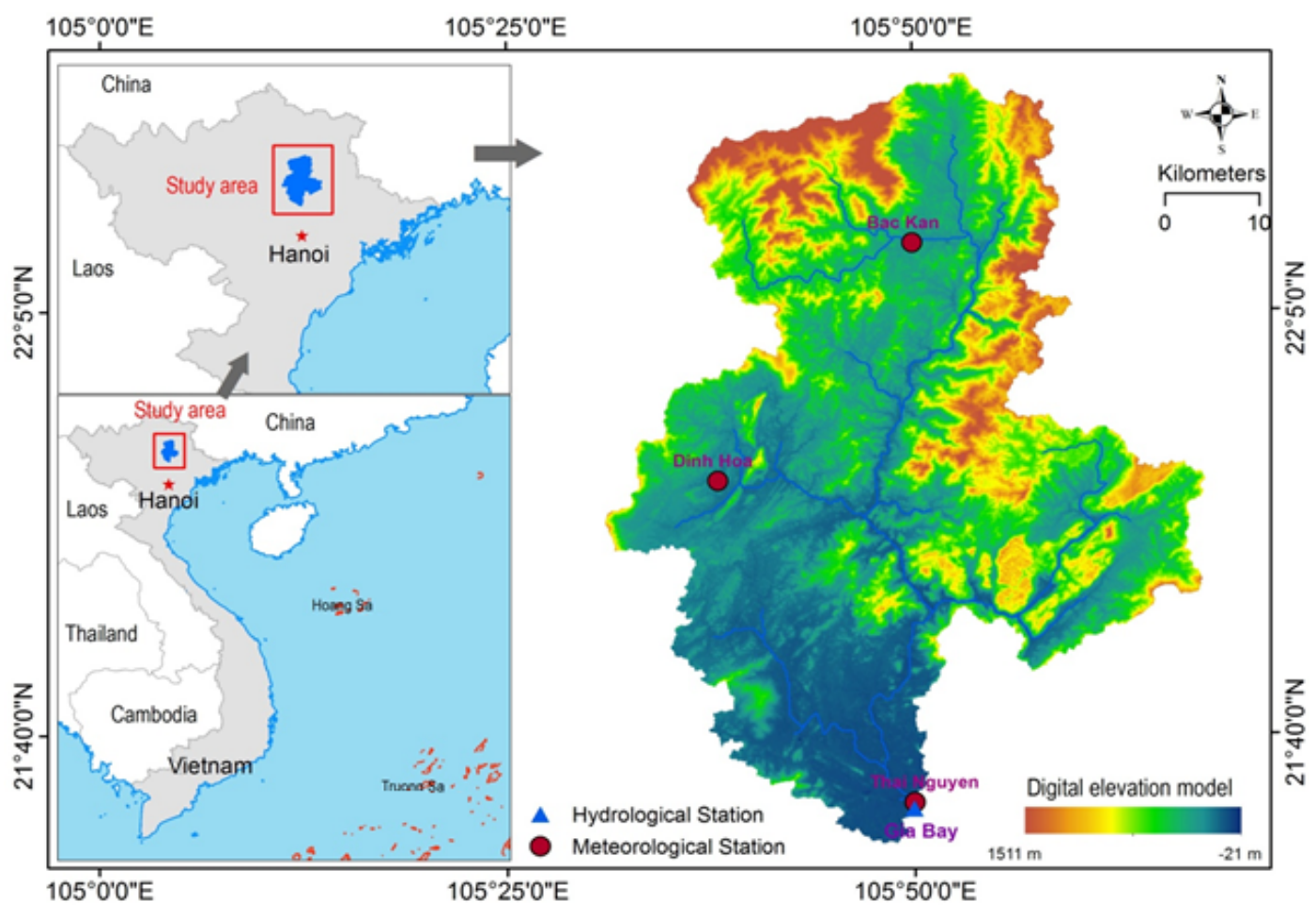

Figure 1. Location of the Upper Cau river basin (Vietnam)

2.2.1. Digital elevation model, land use and soil type

In order to define sub-basins for the study areas, a Digital Elevation Model (DEM) with $90 \mathrm{~m}$ resolution that is available at National Map Seamless Data Distribution System (USGS) was used. Based on the DEM, the elevation map (Figure 2a) was derived. For this analysis, the elevation map was generated with 8 categories $(0-200 ; 200-400 ; 400-600$; 600800 ; 800-1000; 1000-1200; 1200-1400; 1400$1500 \mathrm{~m})$. The elevation is compared to sea level rise.

Because sub-basins may consist of hydrologic response units (HRUs) that possess unique land use/management/soil attributes 
Tran Hong Thai, et al./Vietnam Journal of Earth Sciences 39 (2017)

(J. G. Arnold et al., 2012) land use should be used. For this research, a land use map (Figure $2 \mathrm{~b}$ ) was generated using Landsat 8 OLI images (retrieved on 15 September 2013) with a resolution of $30 \mathrm{~m}$. The enhancement process of sharpening (number) of the image to aid interpretation and transformation process of changing image including multi-channel data combination to create a new image was considered. Then, image classification was carried out using the Maximum Likelihood method in the ENVI 4.5 software. Accordingly, the land use map with 9 classes were determined: Forest-evergreen (FRSE), Forest- deciduous (FRSD), hay (HAY), Rock (ROCK), Forest-mixed (FRST), Agricultural Landgeneric (AGRL), Agricultural Land-closegrown (AGRC), Agricultural Land-Row Crops (AGRR), Residential-medium density (URMD). The overall accuracy of the classification is $5 \%$.

The soil type map (Figure 2c) for this study was extracted from the National Pedology map at a scale of 1:100,000. Accordingly, five classes were determined including Yellow brown soil (FRx), Feralit grey soil (ACf), Mountainous humus grey soil $(\mathrm{ACu})$, Red brown soil (FRr), and Rock (LPq).

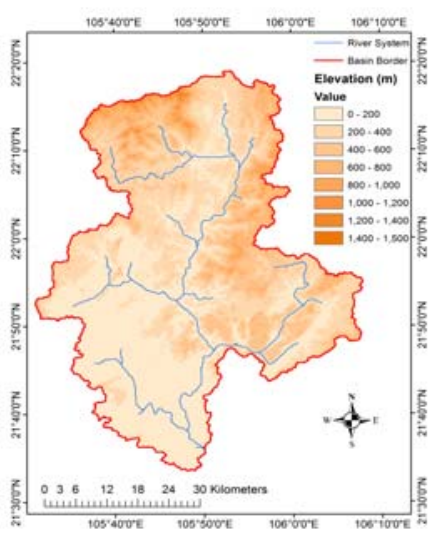

(a)

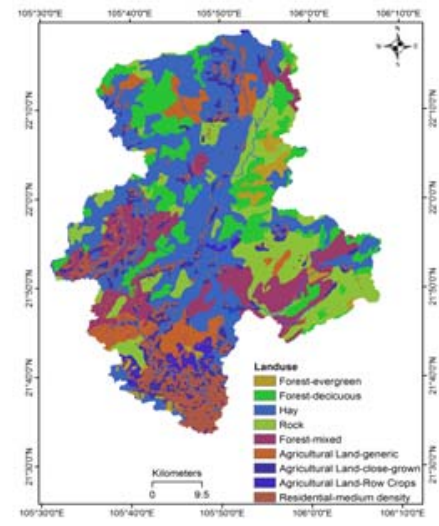

(b)

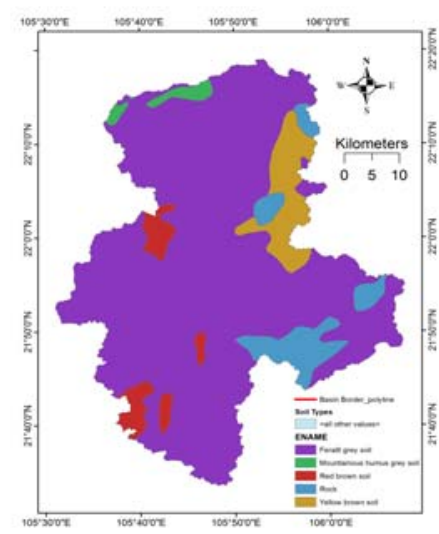

(c)

Figure 2. Maps of Upper Cau River basin: (a) Elevation; (b) Land use in 1993; (c) Soil type

\subsubsection{Climatic data}

Climatic data for the period 1980-1999 were used in this analysis including: (i) daily air temperature (maximum, minimum) $\left({ }^{\circ} \mathrm{C}\right)$; (ii) average daily rainfall (mm); (iii) daily solar radiation $\left(\mathrm{MJ} / \mathrm{m}^{2} /\right.$ day); (iv) daily relative humidity (\%); and (iv) daily wind speed (m/s). All of these data were available at three meteorological stations: Bac Kan, Dinh Hoa, and Thai Nguyen in the basin and were provided by Centre for Hydro-Meteorological Information and Data under the Vietnam HydroMeteorological Service (VHMS) of MONRE
(Vietnam). In addition, the solar radiation was generated to use based on daily maximum and minimum temperature, humidity, wind speed, hour's number of sunshine using the CROPWAT software (FAO). Each factor has been processed using the Microsoft excel software, and then convert to the pdf file for the SWAT model.

In addition, daily temperature and rainfall data under the climate change scenario B2 for the period of 2020-2099 were derived through simulation process using the SDSM and SIMCLIM software (CLIMsystems; Department of Geography) and the results of Global 
Vietnam Journal of Earth Sciences, 39(4), 376-392

Climate Models (GCM), and climate data provided by (MONRE, 2012). The evaporation was derived based on the temperature's increasing trend model that is available at Vietnam Institute of Meteorology, Hydrology and Climate change (IMHEN).

\subsubsection{Hydrological data}

The average monthly discharge $\left(\mathrm{m}^{3} / \mathrm{s}\right)$ for the period 1980-1999 (240 records) and the average monthly sediment discharge $\left(\mathrm{m}^{3} / \mathrm{s}\right)$ for the period 1980-1996 (204 records) were collected. The sediment discharge was processed and transferred to the sediment load (tons/day) for each month in the form of the column. There monitoring data were derived from the Gia Bay hydrological station and also from VHMS.

\subsection{Methodology}

Figure 3 describes the methodology used in this study using the SWAT model that is a river basin or watershed scale model developed to predict the impact of land management practices on water, sediment, and agricultural chemical yields in large, complex watersheds with varying soils, land use and management conditions over long periods of time. Detailed explanations on the SWAT model could be found in (J. G. Arnold et al., 2012) and (Winchell, Srinivasan, Di Luzio, \& Arnold, 2013).

\section{Step 1: Construction of the GIS database}

First, a GIS database for the study area was constructed the SWAT model including (1) Spatial Datasets: Topographic map in the form of DEM with $90 \mathrm{~m}$ resolution; Land use map (in 1993); Soil type map. (2) Climatic Datasets: air temperature (maximum, minimum), average daily wind speed, radiation, relative humidity, rainfall in present time (1980-1999); temperature and rainfall of climate change scenario B2 (3) Hydrological Datasets: average monthly discharge (19801999) and sediment discharge (1980-1996).

\section{Step 2: Determination of sub-watersheds}

Using the DEM, the study area was divided into 35 sub-basins, and then, these subbasins were further divided into hydrologic response units (HRUs) based on land use, topographical and soil characteristics. Accordingly, a total of 355 HRUs were derived.

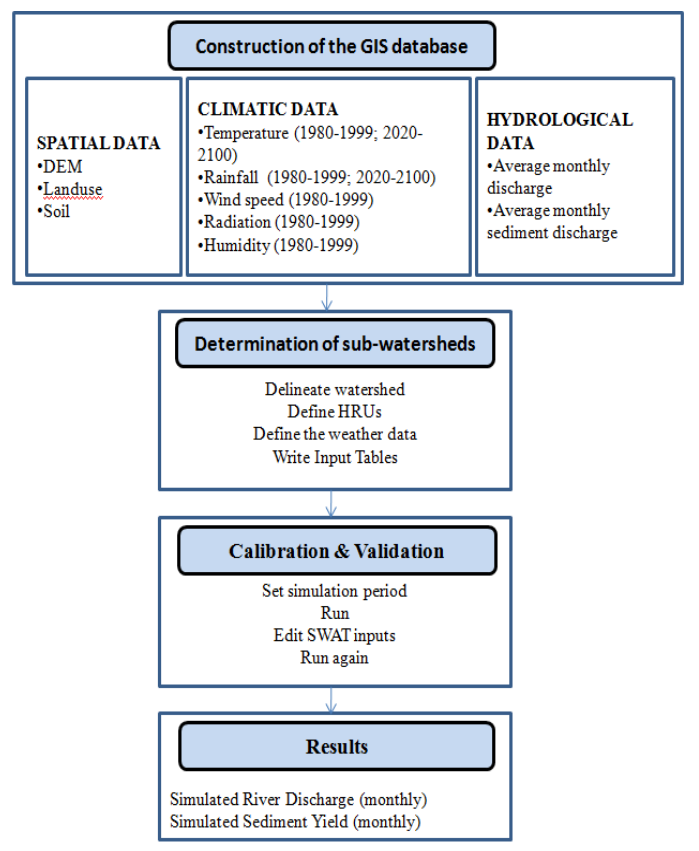

Figure 3. Flow chart of the methodology used in this study

\section{Step 3: Model calibration and validation}

The SWAT model for the study area was calibrated and then was validated using monthly-observed stream flow and sediment discharge at the Gia Bay station. More specifically, the data of monthly discharge of the period 1980-1999 (base period) was divided into 2 periods: 1991-1999 and 1980-1990 for calibration and validation, respectively. Similarly, for monthly sediment data, calibration and validation processes periods were 19811990 and 1991-1996.

The Nash-Sutcliffe and Percent bias (PBIAS) method was used to validate the 
model, and in general, the simulation model can be judged as a satisfactory if NSE $>0.50$ and if PBIAS $\pm 25 \%$ for stream flow, PBIAS $\pm 55 \%$ for sediment. Table 1 and Table 2 show the level of model simulations corresponding to Nash and PBIAS index.

Table 1. The level of model simulations corresponding to Nash index

\begin{tabular}{|c|c|c|c|c|}
\hline $\mathrm{R}^{2}$ & $0.9-1$ & $0.7-0.9$ & $0.5-0.7$ & $0.3-0.5$ \\
\hline$\overline{\text { Simulation level }}$ & $\overline{\text { Very good }}$ & Good & $\overline{\text { medium }}$ & Poor \\
\hline
\end{tabular}

Table 2. The level of model simulations corresponding to PBIAS index

\begin{tabular}{|c|c|c|}
\hline No. & Simulation level & Value \\
\hline 1 & Very good & $< \pm 15 \%$ \\
\hline 2 & Good & $\pm 15 \% \leq$ PBIAS $< \pm 30 \%$ \\
\hline 3 & Satisfactory & $\pm 30 \% \leq$ PBIAS $< \pm 55 \%$ \\
\hline 4 & Unsatisfactory & PBIAS $\geq \pm 55 \%$ \\
\hline
\end{tabular}

\section{Step 4: Results}

The results of running SWAT model were the simulated monthly river discharge and sediment yield that would be further analyzed. The average flow and soil loss by periods, the changes of average flow and soil loss by periods under the climate change scenario B2 would be presented.

\section{Results}

\subsection{Model Calibration and Validation}

Tables 3 and 4 show the results of calibration and validation of model parameters for flow and sediment discharge. The results

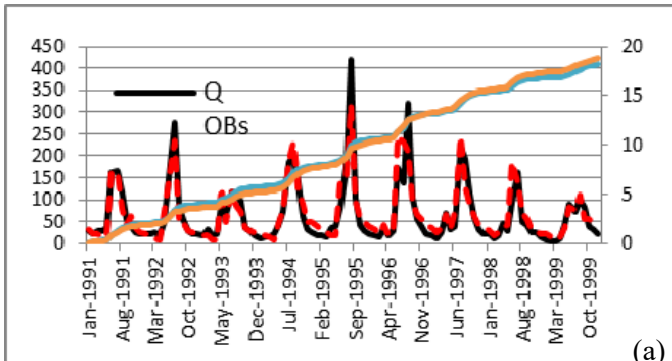

(a) showed that in both calibration and validation process for flow, the values of NASH and PBIAS indexes were with the simulation level from fair and medium to very good. These were considered to be acceptable for simulated outputs of a river basin model like SWAT. The overall adequacy of SWAT to simulate flow and sediment discharge in the watershed indicates its usefulness as a management tool to predict the effects of land use changes in mid-size watersheds. Figure 4 and 5 show the results of observed and simulated discharge and sediment correlation curves and cumulative sum at Gia Bay station, respectively, for both two processes (calibration and validation).

Table 3. Results of calibration and validation of model parameters for flow

\begin{tabular}{ccccc}
\multicolumn{1}{c}{ Process } & Period & Index & Value & Simulation level \\
\cline { 1 - 1 } Calibration 1991-1999 & NASH & 0.85 & & Fair \\
& PBIAS & -3.68 & Very good \\
Validation 1980-1990 & NASH & 0.81 & Fair \\
& PBIAS & -2.54 & Very good \\
\hline
\end{tabular}

Table 4. Results of calibration and validation of model parameters for sediment discharge

\begin{tabular}{|c|c|c|c|c|}
\hline Process & Period & Index & Value & Simulation level \\
\hline \multirow{2}{*}{ Calibration } & \multirow{2}{*}{$1980-1990$} & NASH & 0.66 & Medium \\
\hline & & PBIAS & -10.86 & Very good \\
\hline \multirow{2}{*}{ Validation } & \multirow{2}{*}{ 1991-1996 } & $\mathrm{NASH}$ & 0.58 & Medium \\
\hline & & PBIAS & 11.81 & Very good \\
\hline
\end{tabular}

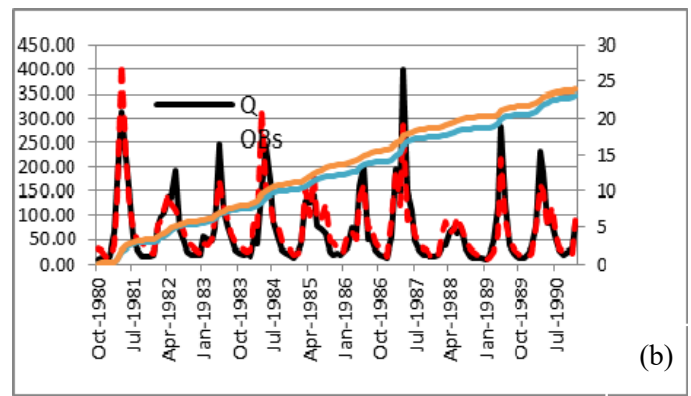

Figure 4. Observed and simulated discharge correlation curves and cumulative sum at Gia Bay station for (a) Calibration process; (b) Validation process 
Vietnam Journal of Earth Sciences, 39(4), 376-392
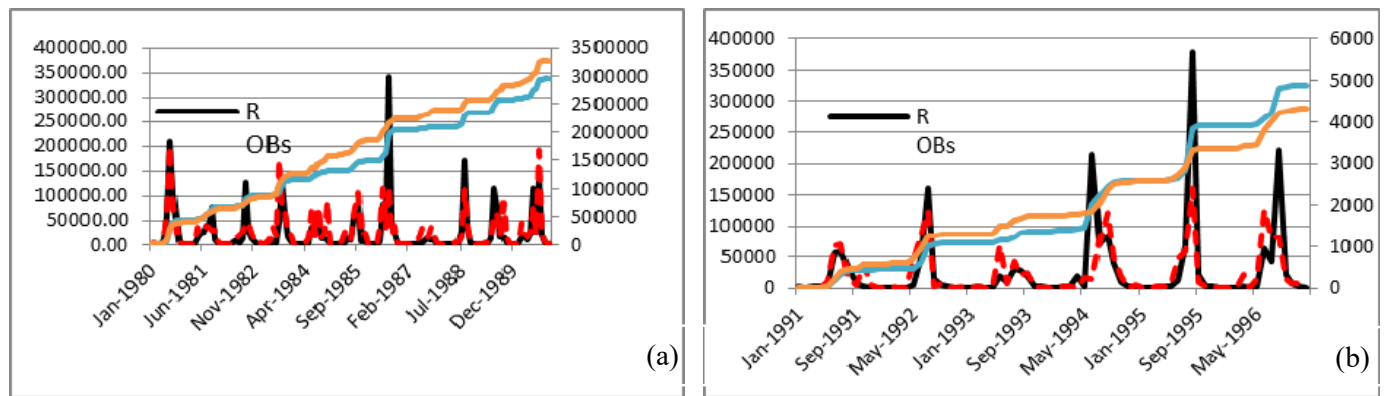

Figure 5. Observed and simulated sediment correlation curves and cumulative sum at Gia Bay station for:

(a) Calibration process; (b) Validation process

\subsection{Impacts of climate change on flow regime and erosion}

Using the SWAT model that was successfully calibrated and validated in the previous section, the simulation of the flow and soil loss at the Gia Bay hydrological station and the sub-basins of the Upper Cau River basin were carried out using the climate change scenario B2. Four periods were considered including 2020-2039, 2040-2059, 2060-2079, 2080-2099.

\subsubsection{Rainfall}

The annual average rainfall at the three stations has the increasing tendency under scenario B2. Compared to the base period, the annual average rainfall in each period has the remarkably increasing trend, the later periods increase faster than the previous ones. In the period of 2020-2039, in the scenario B2, the average annual rainfall increases compared to the base period with $6.4 \%$, similarly, in the periods of 2040-2059, 2060-2079, 2080-2099 with the average rainfall change rate are $7.9 \%$, $9.4 \%, 10.6 \%$, respectively. Rainfall has the tendency of strong increase in rainy season and decrease in the dry season. In the future, the possibility of the flood appearance in rainy season and drought in the dry season goes up in the basin. Figure 6 show the monthly average rainfall by periods under scenario B2 in Upper Cau River basin.

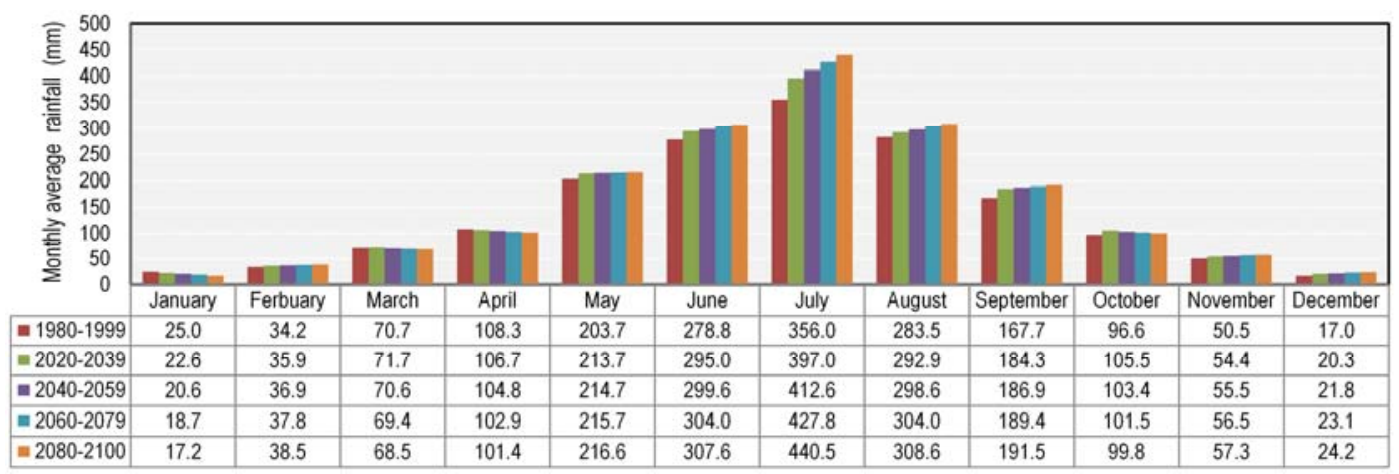

Figure 6. Monthly average rainfall by periods in Upper Cau River basin under B2 scenario

\subsubsection{Temperature}

In general, the annual average temperature in Upper Cau River basin has the increasing trend in the period of 2020-2099 under the impacts of climate change. Figure 7 shows that the three stations have the temperature in the future increased steadily. The Dinh Hoa station 
has the highest annual average temperature with the temperature of $25.3^{\circ} \mathrm{C}$ (2080-2100), followed by the Thai Nguyen station with $24.8^{\circ} \mathrm{C}$ and the least belongs to the Bac Kan station with $24.4^{\circ} \mathrm{C}$.

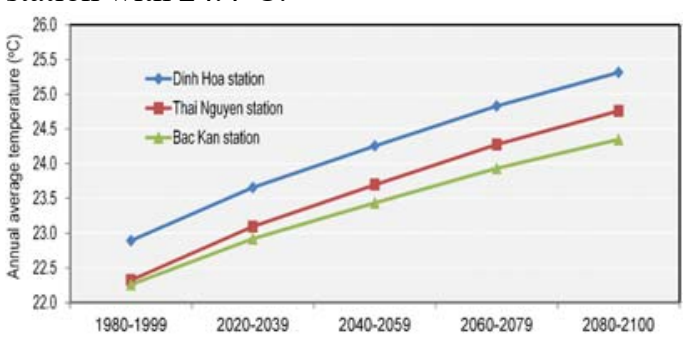

Figure 7. Annual average temperature at stations by periods in Upper Cau River basin under Scenario B2

Compared to the base period 1980-1999, changes of temperature trend is quite similar at the three stations. By the end of the $21^{\text {st }}$ century, temperature rises highly at all three stations, the difference of nearly $3^{\circ} \mathrm{C}$ compared to the base period 1980-1999 under scenario B2.

\subsubsection{Evaporation}

Due to the increase of temperature, potential evaporation in Upper Cau River basin tends to increase in the period of 2020-2100 under climate change scenario B2, however still increase much lower than that of rainfall. Compared to the base period 1980-1999, the changes rate of evaporation goes upward quite steadily and strongest in the end of the century (Figure 8).

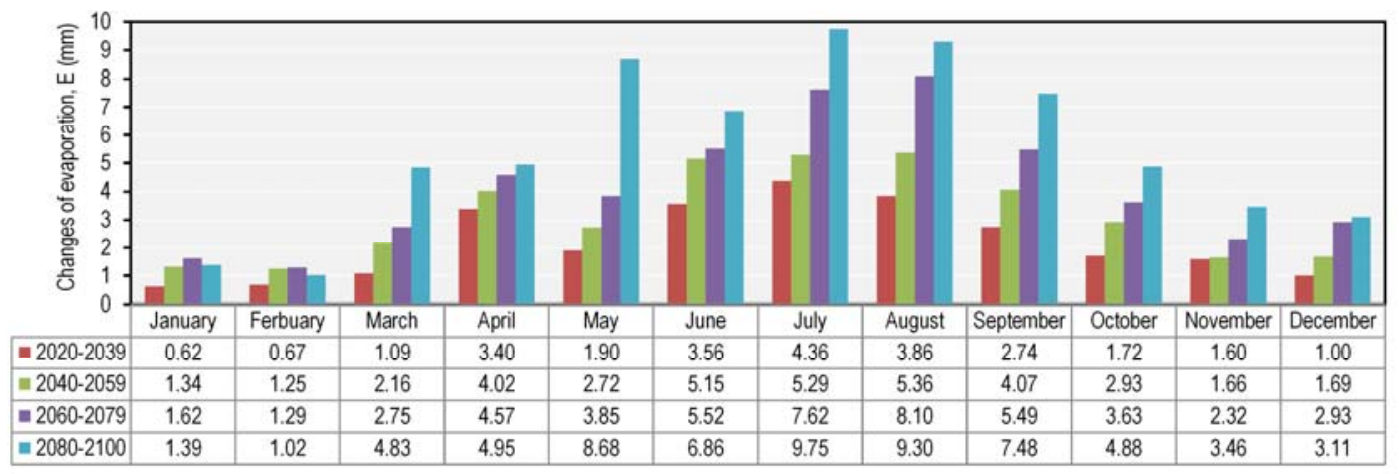

Figure 8. Changes of evaporation in Upper Cau River basin under B2 scenario compared to base period (mm)

\subsubsection{Flow regime changes over time}

The total annual runoff in Upper Cau River system tends to increase compared to the baseline under the climate change scenario B2. The changes rate of the later periods is bigger than the previous ones, appropriate with the changing tendency of evaporation and rainfall of the scenario B2.

The changes of the annual flow in each period are different. In the three periods (20202039, 2040-2059 and 2060-2079) in the climate change scenario B2 the flow increases steadily but in the period of 2080-2099, the flow has the little decreasing trend compared to the other previous periods. Compared to the base period, the flow increases by $0.15 \mathrm{~m}^{3} / \mathrm{s}$ $(0.22 \%)$ in period of $2020-2039$ up to $0.96 \mathrm{~m}^{3} / \mathrm{s}$ $(1.37 \%)(2060-2079)$, then it increases only $0.73 \mathrm{~m}^{3} / \mathrm{s}$ (1.03\%) (2080-2099).

Regarding the monthly average runoff on Upper Cau River basin, at the Gia Bay station, some months like III, IV, V and X, XI, XII show a decreasing runoff tendency while the runoff in VII and VIII has a tendency of increasing. Especially, VI and IX have a decreasing runoff trend in the early half of the century but steadily go up in the last half. With I and II, the runoff increases in the period of 2020-2039 but decreases in the remaining periods. 
Vietnam Journal of Earth Sciences, 39(4), 376-392

Climate change effects on the flow due to the changes of rainfall regime and evaporation. The results of calculating the annual average Rainfall - Evaporation -Runoff and the annual flow coefficient $(\alpha=\mathrm{Y} / \mathrm{X})$ under the
Scenario B2 in Upper Cau river basin restricted at Gia Bay station are shown in Figure 9 and Table 5. The flow coefficient of the river system decreases a little in the scenario B2.

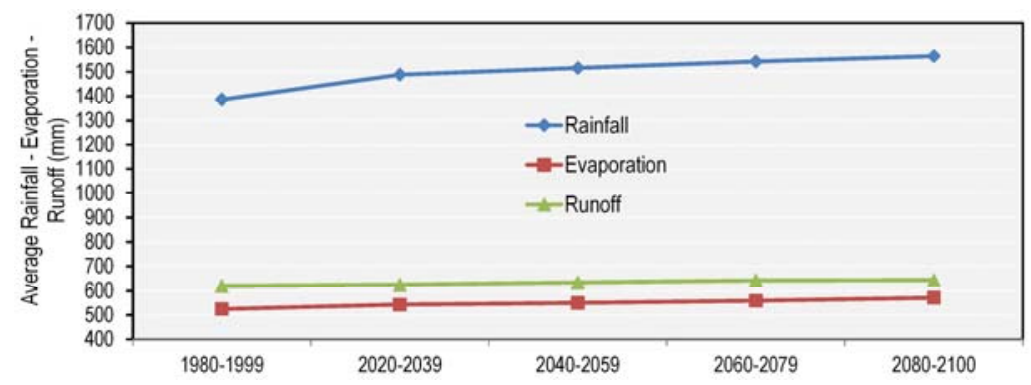

Figure 9. Annual average Rainfall - Evaporation - Runoff by periods in Upper Cau River basin under Scenario B2

Table 5. Rainfall - Evaporation - Runoff calculated upto Gia Bay station - Scenario B2 (mm)

\begin{tabular}{ccccc}
\hline Period & Rainfall & Evaporation & Runoff & Flow coefficient \\
\cline { 5 - 6 } \cline { 5 - 6 } 1980-1999 & 1692.03 & 787.69 & 805.65 & 0.48 \\
$2020-2039$ & 1800.12 & 814.20 & 807.37 & 0.45 \\
$2040-2059$ & 1825.95 & 825.33 & 810.76 & 0.44 \\
$2060-2079$ & 1850.84 & 837.37 & 816.58 & 0.44 \\
$2080-2099$ & 1871.65 & 853.39 & 813.86 & 0.43 \\
\hline
\end{tabular}

The simulated discharge continuity curve at Gia Bay station in the future periods and base period under Scenario B2 is shown in Figure 10. Changes of flow in Upper Cau River basin under B2 scenario compared to base period (\%) is presented in Figure 11.

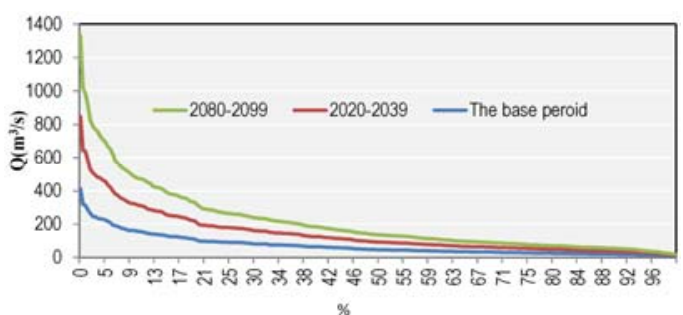

Figure 10. Simulation of discharge at the Gia Bay station for the future periods, 2020-2039 and 2080-2099 using the scenario B2

The flow in flood season has the increasing trend meanwhile it in dry season has the decreasing trend in the entire Upper Cau River basin in the future under the climate change scenario B2. In the period of 2020-2039, the flood-season average flow is $109.3 \mathrm{~m}^{3} / \mathrm{s}$ higher than that in the base period $\left(108.4 \mathrm{~m}^{3} / \mathrm{s}\right)$, and increases up to $112.4 \mathrm{~m}^{3} / \mathrm{s}$ in the last century. Compared to the flow of base period, it increases from $0.88 \mathrm{~m}^{3} / \mathrm{s}(0.81 \%)$ to $4.07 \mathrm{~m}^{3} / \mathrm{s}$ $(3.76 \%)$.

In the period of 2020-2039, the dry-season average flow is $31.7 \mathrm{~m}^{3} / \mathrm{s}$ lower than that in the base period $\left(32.2 \mathrm{~m}^{3} / \mathrm{s}\right)$, and decreases down to $29.6 \mathrm{~m}^{3} / \mathrm{s}$ in the last century. Compared to the flow of base period, it decreases from $0.57 \mathrm{~m}^{3} / \mathrm{s} \quad(-1.78 \%)$ down to $-2.62 \mathrm{~m}^{3} / \mathrm{s}$ $(-8.12 \%)$. Regarding the flow distribution in the year, the flood-season flow has the decreasing trend in the beginning month of the flood season (May), then increasing strongly in the middle months of the season (from June to September), in the end, (October) it decreases steadily again. While the dry-season flow has the decreasing trend from the middle months of the dry season (January, February) and decreases strongest in the end month (April), 
Tran Hong Thai, et al./Vietnam Journal of Earth Sciences 39 (2017)

the beginning months have the considerable decreasing rate. The changes rate of the annual average, flood-season, and dry-season flow compared to the base period at Gia Bay station under the climate change scenario B2 is presented in Figure 12.

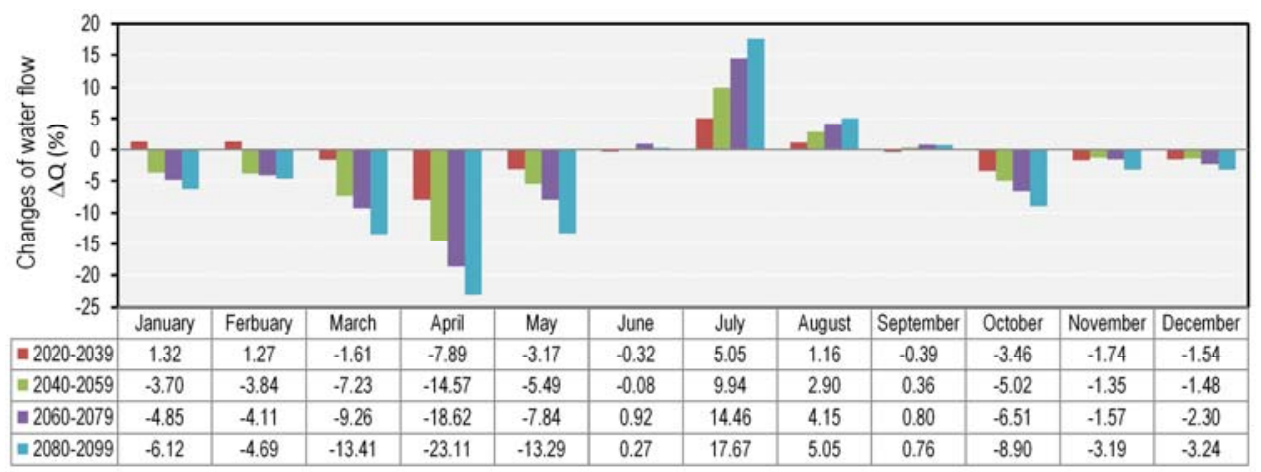

Figure 11. Changes of flow in Upper Cau River basin under B2 scenario compared to baseline period (\%)

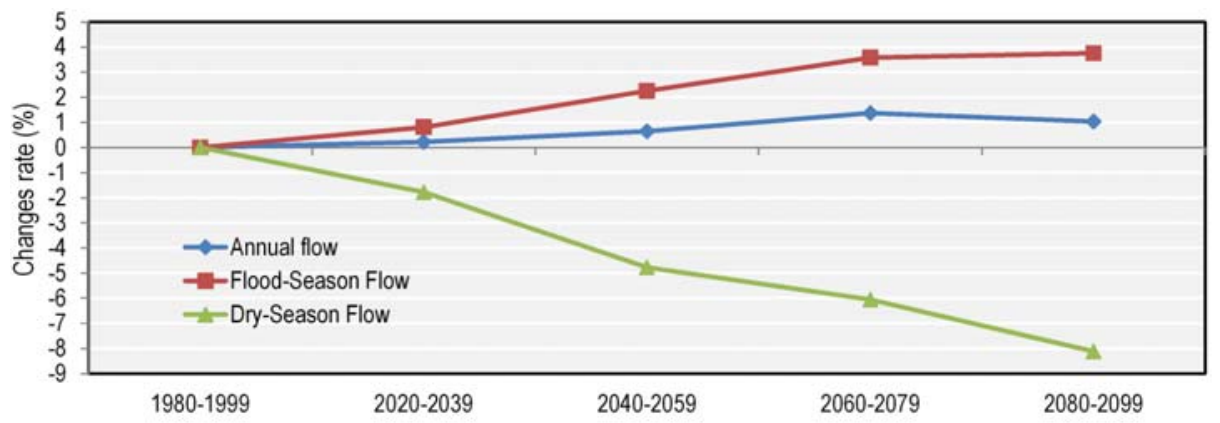

Figure 12. The changes rate of the annual average, flood-season and dry-season flow compared tothe base period at Gia Bay station under the CC scenario B2

\subsubsection{Soil loss changes over time at Gia Bay station}

The total annual soil loss (tons) at Gia Bay station tends to increase steadily compared to the baseline under the climate change scenario B2. Compared to the base period, the average soil loss at Gia Bay station increases by 16642 tons $(6.2 \%)$ in period of $2020-2039$ and goes upward to 68951 tons $(25.5 \%)$ in the last period of the century. Figure 13 presents the changes rate of average soil loss by periods compared to the base period under the scenario B2 at Gia Bay station (\%).

In flood season, at Gia Bay station, the total annual soil loss (tons) tends to increase steadily while in the dry season it has decreasing tendency compared to the baseline under the climate change scenario B2. Compared to the base period, the changes of average soil loss in flood season at Gia Bay station increases by 18249 tons (7.5\%) in the period of 2020-2039 up to 72933 tons $(29.9 \%)$ in the last period of the century (2080-2099). However, in the dry season, the changes of average soil loss decreases by -1652 tons $(-6.2 \%)$ in the period of 2020-2039 down to -3982 tons $(-14.8 \%)$ in the last period of the century (2080-2099). Figure 14 shows the average soil loss (tons) in flood season (a) and dry season (b) by periods at Gia Bay station under the climate change scenario B2 in Upper Cau River basin. 
Vietnam Journal of Earth Sciences, 39(4), 376-392

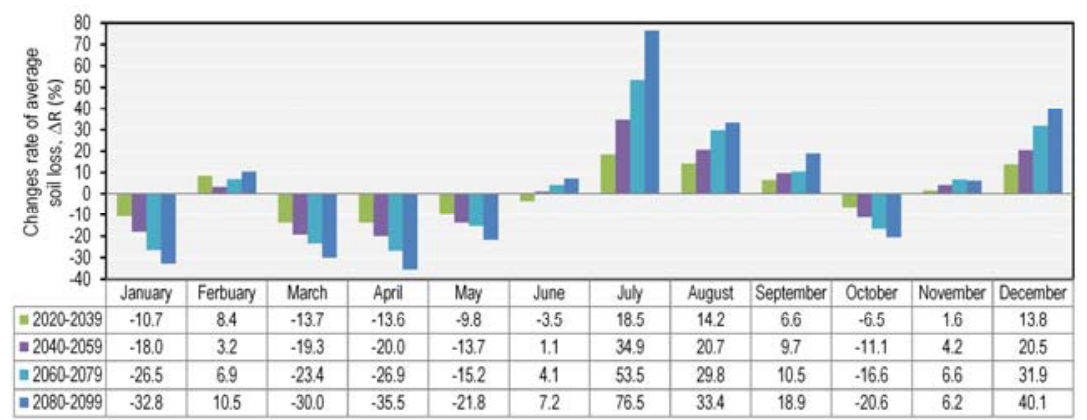

Figure 13. The changes rate of average soil loss by periods under scenario B2 compared to the base period at Gia Bay station (\%)

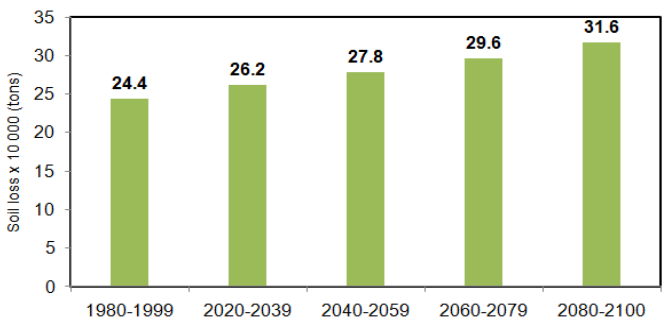

(a)

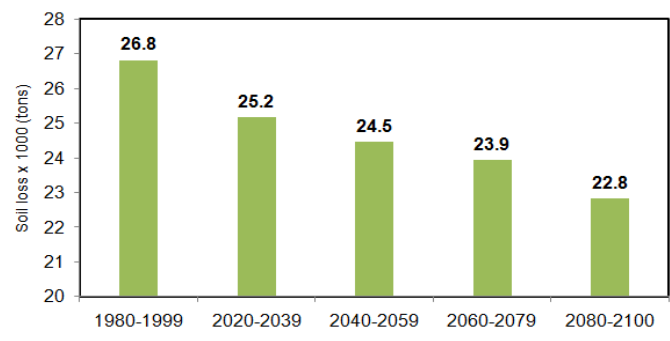

(b)

Figure 14. The average soil loss in flood season (a) and dry season (b) by periods at Gia Bay station - Scenario B2

\subsubsection{Soil loss distribution in sub-basins}

Based on the classification regulations of erosion status according to Vietnam standard (Vietnam soil quality, TCVN 5299-1995), the study area was divided into 4 erosion levels in the period of 1980-1999 (Table 6). The results showed that the erosion status of the basin has uneven areas among erosion levels. The erosion level I accounts for the most area with $61.2 \%$ of the total, twice times compared to that of level II with $37.5 \%$. Meanwhile, the erosion level III and IV in the basin only makes up $0.9 \%$ and $0.4 \%$, respectively. The total soil loss is 1164.6 tons/ha/year.

Table 6. Erosion classification (1980-1999)

\begin{tabular}{|c|c|c|c|c|}
\hline No. & Erosion level & Soil loss (tons/ha/year) & Area (ha) & Rate $(\%)$ \\
\hline 1 & Level I & $0-10$ & 173473.8 & 61.2 \\
\hline 2 & Level II & $10-50$ & 106260.9 & 37.5 \\
\hline 3 & Level III & $50-200$ & 2673.0 & 0.9 \\
\hline 4 & Level IV & $>200$ & 1103.2 & 0.4 \\
\hline \multicolumn{3}{|c|}{ Total } & 283510.9 & 100 \\
\hline
\end{tabular}

Figure 15 represents the annual soil loss in 35 sub-basins in Upper Cau River basin in the period of 1980-1999. Figure 16 shows the annual soil loss in sub-basins in Upper Cau River basin in the four periods of the future: 2020-2039, 2040-2059, 2060-2079, 20802099. Compared to the base period 1980-1999, the erosion status of the Upper Cau River basin has the increasing trend with more annual soil loss.

The erosion status in flood season of the basin under the impacts of $\mathrm{CC}$ has an increasing tendency meanwhile in the dry season it has a decreasing tendency, 
Tran Hong Thai, et al./Vietnam Journal of Earth Sciences 39 (2017)

appropriate with increasing trend of rainfall and flow in the Upper Cau River basin in flood season (Figure 17). The percentage rate of flood season and dry-season soil loss in the future compared to base period is presented in Figure 18 and Figure 19.

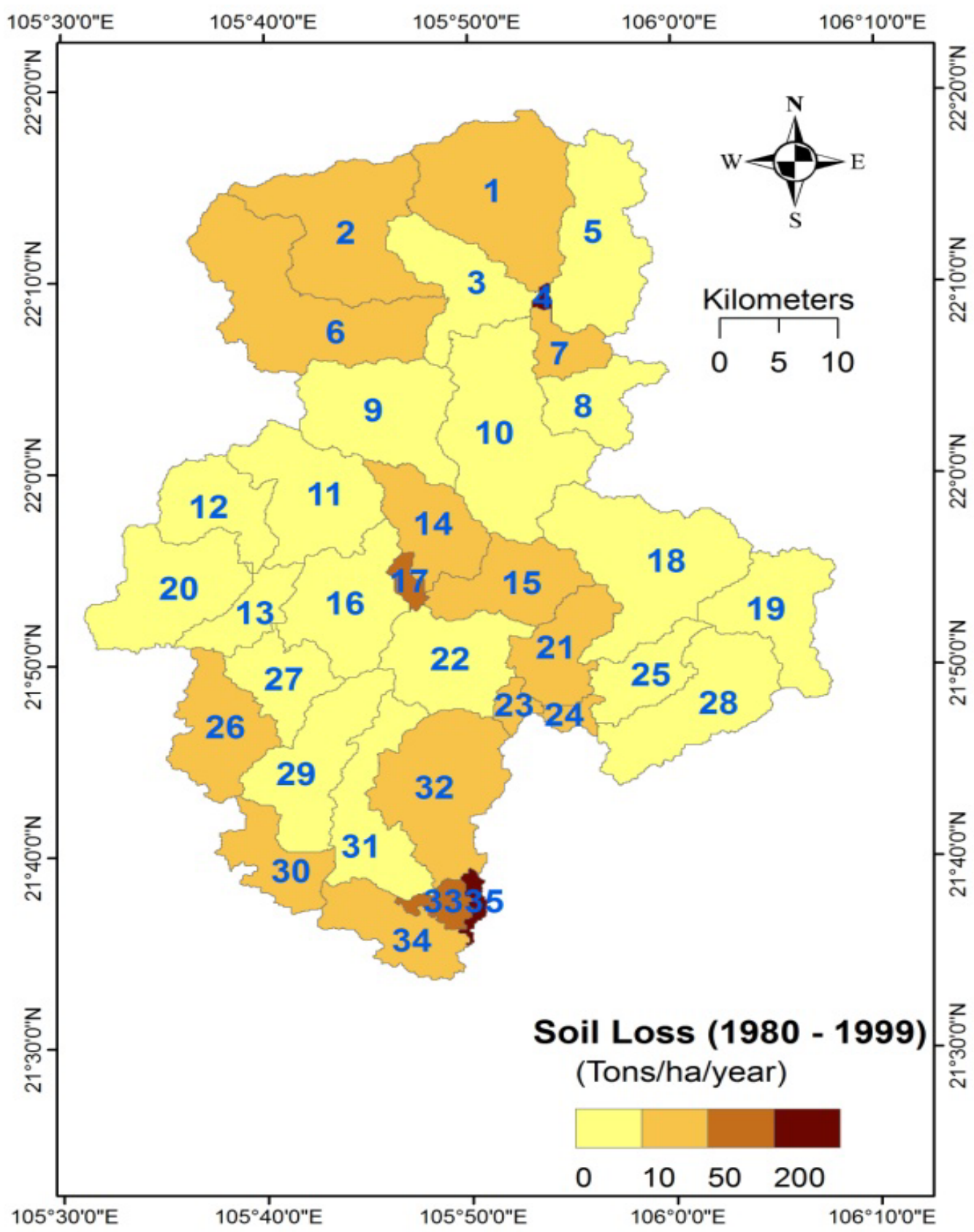

Figure 15. The annual soil loss in sub-basins in Upper Cau River basin - Period 1980-1999 
Vietnam Journal of Earth Sciences, 39(4), 376-392

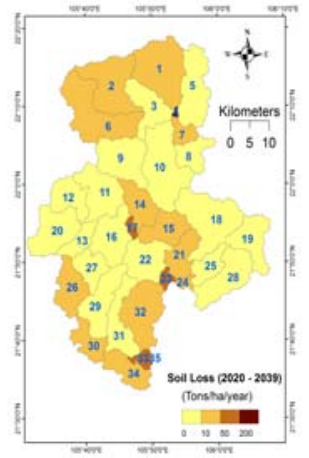

(a)

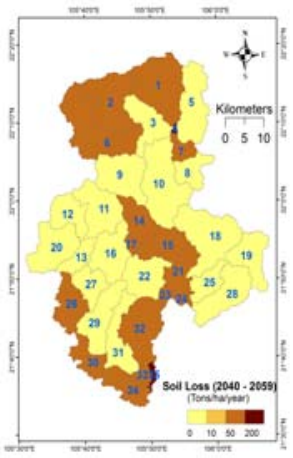

(b)

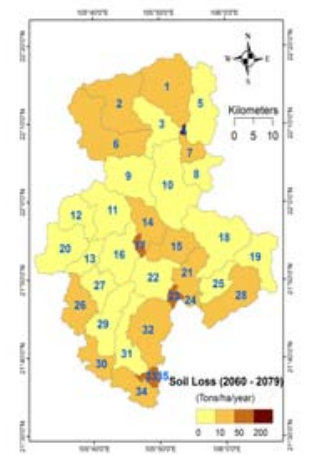

(c)

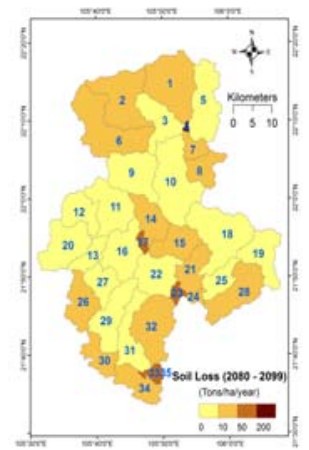

(d)

Figure 16. The annual soil loss in sub-basins in Upper Cau River basin by periods in the future: (a) Period 2020-2039, (b) Period 2040-2059, (c) Period 2060-2079, (d) Period 2080-2099

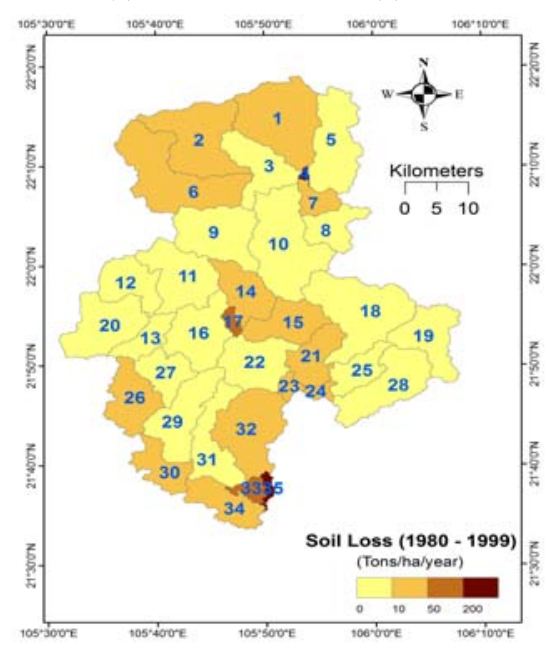

(a)

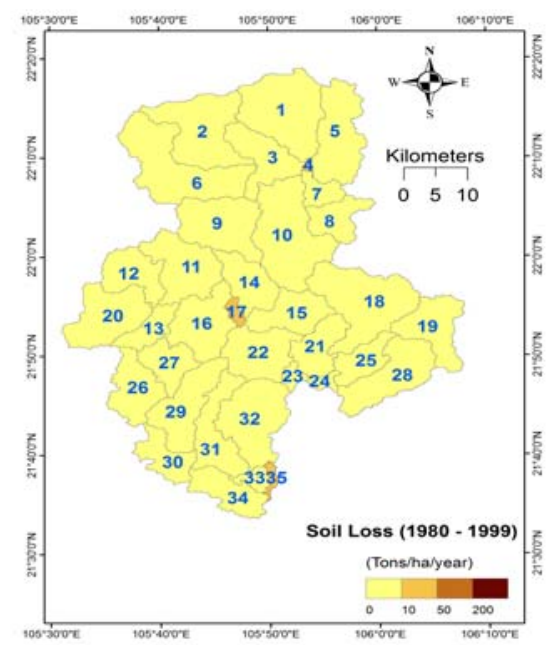

(b)

Figure 17. The soil loss in flood season (a) and dry season (b) in sub-basins in Upper Cau River basin - Period 1980-1999

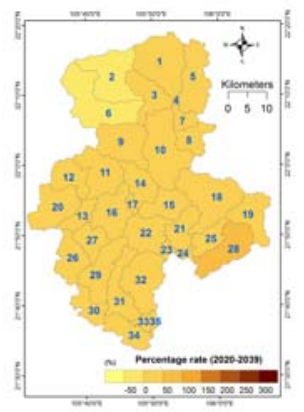

(a)

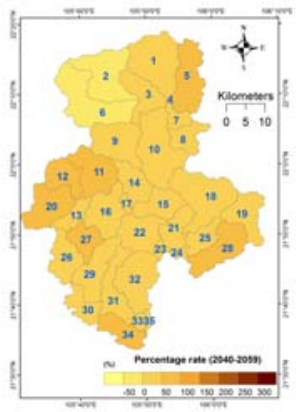

(b)

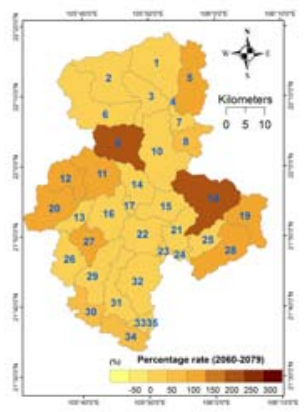

(c)

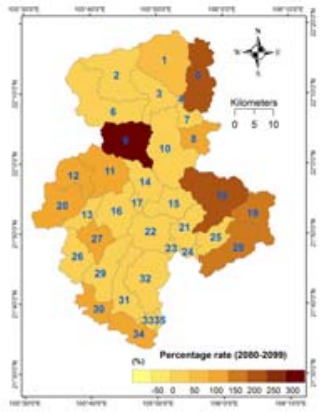

(d)

Figure 18. Percentage rate of flood-season soil loss by periods in the future compared to base period: (a) Period 2020-2039, (b) Period 2040-2059, (c) Period 2060-2079, (d) Period 2080-2099 
Tran Hong Thai, et al./Vietnam Journal of Earth Sciences 39 (2017)

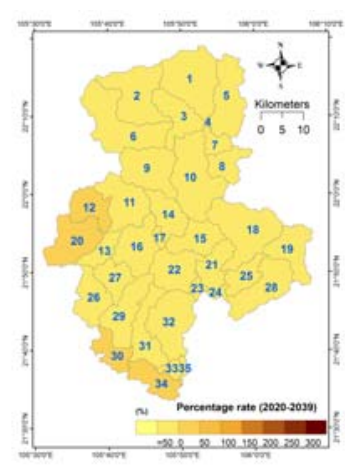

(a)

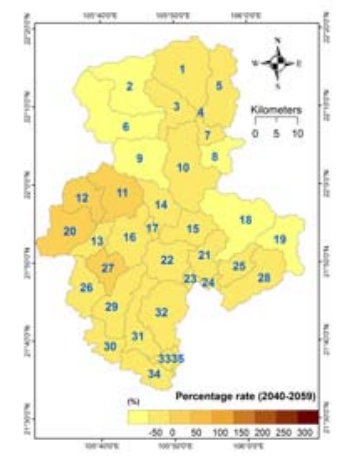

(b)

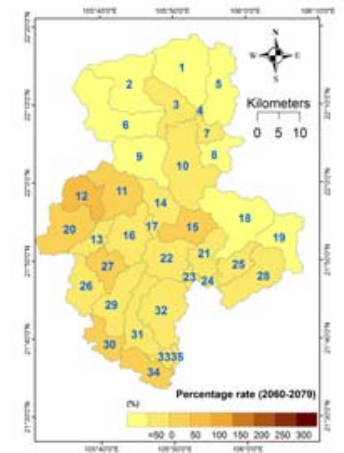

(c)

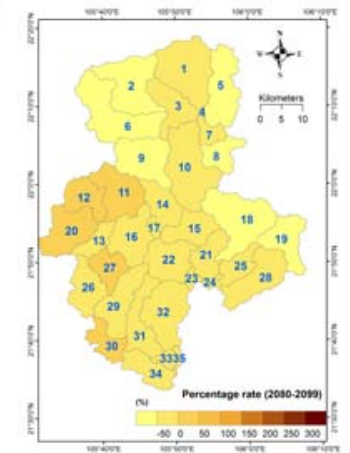

(d)

Figure 19. Percentage rate of dry-season soil loss by periods in the future compared to base period:

(a) Period 2020-2039, (b) Period 2040-2059, (c) Period 2060-2079, (d) Period 2080-2099

\section{Discussions}

In recent years, application of models has become an indispensable tool for the understanding of the natural processes. Dominantly, SWAT model is one of the most widely used watershed-scale simulation tools and bringing the most effective results when studying in soil erosion and water resources (Arnold J.G. and Fohrer, 2005) described the expanding global use of SWAT which has been employed widely to evaluate the impact of climate change on soil erosion and sediment flux (Li Y., et al., 2011) applied SWAT to evaluate the effect of temperature change on water discharge, and sediment and nutrient loading in the Lower Pearl River basin, China (Hanratty M.P. and Stefan H.G., 1998) have also described the application of SWAT to evaluate the impact of climate change on sediments in an agricultural watershed in Minnesota and in five European catchments. Due to the spatial and temporal heterogeneity in soils properties, vegetation, and land use practices, a hydrological cycle is a complex system (Rossi et al., 2009) evaluated in hydrologic perspective the lower Mekong river basin.

In Vietnam, there are series of studies implemented on water resources in many river basins and specific provinces aiming to contribute to the government's planning and river basin management. Aspects of water resources such as quantity and quality have been mentioned (Son N.T. et al., 2011) analyzed the changes of water resources on Nhue-Day River basin under the impacts of climate change, while (Nhu N.Y., 2011) focused on the extreme of the flow in the same study area. However, they only used the future scenarios of 2020, 2050 compared to the baseline period of 1970-1999. Using SWAT model and GIS (Liem N.D. et al., 2011) had a study on assessing water discharge in Be river basin, which is an important hydrological parameter that defines the shapes, size, and course of the stream. The study focused to quantify the impact of topographic, land use, soil and climatic condition on water discharge. SWAT in combination with GIS has identified clearly the objectives of the study with the capacity of enhancing the precision of flow simulation results from rainfall and physical characteristics of the basin.

Additionally, a wide range of studies has been conducted on soil erosion issue in many parts of Vietnam using lots of research methods. Taking some examples such as in Vo Nhai district in Thai Nguyen province; Da Tam watershed in Lam Dong province (Tu L.H. et al., 2011); Tam Nong Commune in Phu Tho province (Thang, 2010); Tay Nguyen region; Son La province; Dong Nai river basin, etc. 
Vietnam Journal of Earth Sciences, 39(4), 376-392

(Binh N.D. et al., 2010) used modelling and web technologies to assess the level of soil erosion in northwestern region of Vietnam in general. In Dakrong Commune, Quang Tri province (Trong T.D. et al., 2012) used RMMF (Revised Morgan-Morgan-Finney) model to find out the soil erosion possibility. Utilizing USLE, for instance (Chau T.L.M. et al., 2011) implemented a study about soil erosion management in Hue province.

Taking into account climate change, the study of (Phan D.B. et al., 2011) also used SWAT to assess its impacts on stream discharge and sediment yield in Phu Luong watershed in Northern Vietnam. Results showed that the stream discharge was likely to increase in the future during the wet season with increasing threats of sedimentation. Conducted by the same author's group with the same model tool, another study of (Phan D.B. et al., 2011) implemented in Cau River basin, Vietnam. This study used three climate change scenarios B1, B2, and A2 to assess but only showed the seasonal values, not the monthly though climate change is needed to express the extent of more details. Additionally, the study just gave the comparison of stream discharge and sediment load change between only 3 decades of the 2020s, 2030s, and 2050s with the baseline period. To satisfy those deficiencies in Phan's research, this paper used the data from the future from 2020 up to 2100 - a long enough period - focusing fundamentally on just one scenario B2 to perform the changes of stream discharge and sediment yield of the Upper Cau river basin and went into details in each month and season in year. Furthermore, the output of Phan's study just stopped at changes of sediment yield without describing the process of surface erosion with its levels that could have been shown apparently in maps. The paper would fill with it. Also, this paper would also combine results from remote sensing with surveyed land use map to make it more accurate thereby create more precise inputs for SWAT model.
From the results of this study, the calibration and validation processes show that SWAT is capable of simulating the flow with the conditions of the study area with relatively high accuracy. On the other hand, for sediment discharge, one of the reasons causing the discrepancy between simulated and observed sediment discharge may be attributed to channel erosion, especially during high flows and instability of sediment yields. Other factors include SWAT's inadequate description of channel scouring process and the presence of temporary channel embankment used by farmers to retard channel flow velocity. Moreover, the small number of meteorological stations in the basin is also one of the reasons for that. Nevertheless, these results ensure the calibrated parameters are suitable to be used to assess the flow and sediment changes under the context of climate change. The overall adequacy of SWAT to simulate flow and sediment discharge in the watershed indicates its usefulness as a management tool to predict the effects of land use changes in mid-size watersheds.

\section{Conclusions}

From the results, in Upper Cau River system, it includes that the total annual runoff tends to increase compared with the baseline under the climate-change scenario B2. The change's rate of the later periods is bigger than the previous ones, appropriate with the changing tendency of evaporation and rainfall, which are the most important factors affecting on the flow regime (rainfall increases much but evaporation increases less leading to annual runoff increase). The impacts of climate change in the flow regime are presented apparently inflow variation in flood and dry season in future periods. The imbalance in the flow distribution throughout the year is shown in the considerably increasing trend of flow in flood season and decreasing trend in dry season. It means that floods occur more frequent- 
Tran Hong Thai, et al./Vietnam Journal of Earth Sciences 39 (2017)

ly with the larger amount of discharges in rainy season, while water shortage and drought would be more serious in dry season. Moreover, increasing in total annual runoff also affects the erosion status in the basin. It would in general increase the total annual sediment load (soil loss). At Gia Bay station, the total annual soil loss (tons) tends to increase steadily compared with the baseline under the climate-change scenario B2. Especially, in the flood season, greater variability in daily precipitation distribution led to increased occurrence of large storms and therefore, greater stream discharge and soil loss, leading to at Gia Bay station; the soil loss has been increasing trend. On the contrary, in dry season, it decreases gradually compared with the period of 1980-1999. With regards to the erosion status classification during the base period (1980-1999), the annual soil loss was divided into four erosion levels, which are distributed in different areas. The effect of climate change on soil erosion is also not homogeneous throughout the basin. The soil loss distribution is different among 35 sub-basins. Through the analysis, the results from the study revealed that under the climate-change scenario B2, the climate trends in Upper Cau river basin are leading to severe conditions for runoff generation as well as erosion status due to an increase in evaporation and rainfall during the period of 2020-2099. Additionally, applying SWAT model and GIS technique is fairly accurate helping managers easily identify severity levels of flow regime and areas having high possibility of soil erosion in the basin in the context of climate change, thereby, making appropriate measures in the future in order to limit the effects of these processes on daily life and the production and business activities of the local people.

\section{References}

Ali R., McFarlane D., Varma S., Dawes W., Emelyanova I., Hodgson G., Charles S., 2012.
Potential climate change impacts on groundwater resources of south-western Australia. Journal of Hydrology, 475, 456-472. Doi.org/10.1016/j.jhydrol.2012.04.043

Arnell N. W., 2004. Climate change and global water resources: SRES emissions and socio-economic scenarios. Global Environmental Change, 14(1), 3152. Doi:10.1016/j.gloenvcha.2003.10.006

Arnold J. G., Fohrer N., 2005. SWAT2000: Current capabilities and research opportunities in applied watershed modeling. Hydrol. Proc., 19(3), 563-572.

Arnold J.G., Kiniry J.R., Srinivasan R., Williams J.R., Haney E.B., Neitsch S.L., 2012. Soil and water assessment tool. Input/output Documentation: Texas Water Resources Institute.

Beare S., Heaney A., 2002. Climate Change and water resources in the Murray Darling Basin, Australia, impacts and possible adaptation. Paper presented at the World Congress of Environmental and Resource Economists, Monterey, California, USA.

Binh N.D., Tuan N.A., Huong H.L., 2010. SWAT application coupled with web technologies for soil erosion assessment in north western region of Vietnam. Paper presented at the International SWAT Conference Mayfield Hotel. Seoul, South Korea: Hanoi University of Algriculture.

Chau T.L.M., Tuan N.Q., 2011. Application of SWAT for soil erosion management at river subbasins in Duong Hoa commune, Huong Thuy town, Thua Thien Hue province. Paper presented at the 3rd National GIS conference Da Nang University of Education, Da Nang, Vietnam.

CLIMsystems. http://www.climsystems.com/simclim/.

Department of Geography, L. U. SDSM Statistical Downscaling Model:

http://copublic.lboro.ac.uk/cocwd/SDSM/software.html.

FAO. http://www.fao.org/land-water/databases-andsoftware/cropwat/en/.

Hanratty M.P., Stefan H.G., 1998. Simulating climate change effects in a Minnesota agricultural watershed. J. Environ. Qual., 27, 1524-1532.

IPCC, 2000. Special Report on Emissions Scenarios. United States of America.

IPCC, 2007. Fourth Assessment Report: Climate Change 2007 (AR4). 
Vietnam Journal of Earth Sciences, 39(4), 376-392

Li Y., Chen B.M., Wang Z.G., Peng S.L., 2011. Effects of temperature change on water discharge, and sediment and nutrient loading in the lower Pearl River basin based on SWAT modeling. Hydrolog. Sci. J., 56, 68-83.

Liem N.D., Hong N.T., Minh T.P., Loi N.K., 2011. Assessing water discharge in $\mathrm{Be}$ river basin, Vietnam using GIS and SWAT model. Paper presented at the National GIS application Vietnam. http://gisnetwork.vn/wpcontent/uploads/2012/04/GIS 2011_BAI1.swf.

McBean E., Motiee H., 2008. Assessment of impact of climate change on water resources: a long term analysis of the Great Lakes of North America. Hydrology and Earth System Sciences, 12, 239-255.

MONRE, 2009. Climate Change, Sea level rise scenarios for Vietnam. Vietnam.

MONRE, 2012. Climate Change, Sea level rise scenarios for Vietnam. Vietnam.

MONRE, 2016. Climate Change, Sea level rise scenarios for Vietnam. Vietnam.

Nhu N.Y., 2011. Researching on the impacts of Climate Change on the extreme of the flow on Nhue-Day rivers basin, Hanoi. (Master), Hanoi University of Science, Hanoi National University, Vietnam.

Ouyang W., Gao X., Hao Z., Liu H., Shi Y., Hao F., 2017. Farmland shift due to climate warming and impacts on temporal-spatial distributions of water resources in a middle-high latitude agricultural watershed. Journal of Hydrology, 547, 156-167. doi.org/10.1016/j.jhydrol.2017.01.050.

Phan D.B., Wu C.C., Hsieh S.C., 2011. Impact of Climate Change and Deforestation on Stream Discharge and Sediment Yield in Phu Luong Watershed, Vietnam Environmental Science and Engineering, 5, 1063-1072.
Phan D.B., Wu C.C., Hsieh S.C., 2011. Impact of Climate Change on Stream Discharge and Sediment Yield in Northern Vietnam. Water Resources, 38(6), 827-836. Doi: 10.1134/S0097807811060133.

Rossi C.G., Srinivasan R., Jirayoot K., Duc T.L., Souvannabouth P., Binh N.D., Gassman P.W., 2009. Hydrologic evaluation of the lower Mekong river basin with the soil and water assessment tool model. International Agricultural Engineering, 18, 1-13.

Son N.T., Tuan N.C., Hang V.T., Nhu N.Y., 2011. Impact of climate change on water resources to transform Nhue-Day rivers basin. Natural and Technological Science, 27, 218-226.

Thang T.Q., 2010. Application of remote sensing images and GIS technique to assess soil erosion in Tam Nong Commune, Phu Tho province. Master. Hanoi University of Agriculture, Hanoi.

Trong T.D., Viet N.Q., Huong D.T.V., 2012. Assessing the soil erosion possibility in Dakrong Commune, Quang Tri province using RMMF (Rrevised Morgan-Morgan-Finney) model. Scientific Journal, Hue University, Vietnam, 74A(5), 173-184.

Tu L.H., Liem N.D., Minh T.P., Loi N.K., 2011. Assessing soil erosion in Da Tam watershed, Lam Dong province using GIS technique Paper presented at the National GIS application Da Nang, Vietnam.

USGS. National Map Seamless Data Distribution System.

Vargas-Amelin E., Pindado P., 2014. The challenge of climate change in Spain: Water resources, agriculture and land. Journal of Hydrology, 518(B), 243-249. Doi.org/10.1016/j.jhydrol.2013.11.035.

Winchell M., Srinivasan R., Di Luzio M., Arnold J., 2013. ArcSWAT Interface for SWAT 2012. User's Guide. Texas: Blackland Research and Extension Center; Grassland Soil and Water research laboratory. 